\title{
Comparison of Accommodation Microfluctuations before and after 5 Minutes Near Digital Reading in the dark with Night Shift Mode
}

\author{
Aresya Najmee, Ai-Hong Chen, Saiful Azlan Rosli, Nursyuhadah Azni \\ Department of Optometry, Faculty of Health Sciences, \\ Universiti Teknologi MARA Cawangan Selangor 42300 Bandar Puncak Alam, Selangor Malaysia \\ aresyanajmee@uitm.edu.my, chenaihong@uitm.edu.my, saifulazlan010@gmail.com,nursyuhadaazni@gmail.com \\ Tel: +60179450024
}

\begin{abstract}
This study aims to compare the accommodation microfluctuation before and after 5 mins of digital reading in the dark with night shift mode. Nineteen subjects were recruited using convenient sampling and a crossover design was used to compare the accommodation microfluctuations two viewing conditions. There was no significant difference in accommodation microfluctuations before and after 5-minute reading with night shift mode and without night shift mode. The insignificant findings in the accommodation microfluctuation comparison seemed to suggest that Night Shift Mode did not display as an advantage in controlling accommodation.
\end{abstract}

Keywords: Digital eye strain, accommodation microfluctuations, digital reading, night shift mode.

eISSN: 2398-4287@ 2020. The Authors. Published for AMER ABRA cE-Bsby e-International Publishing House, Ltd., UK. This is an open access article under the CC BYNC-ND license (http://creativecommons.org/licenses/by-nc-nd/4.0/). Peer-review under responsibility of AMER (Association of Malaysian Environment-Behaviour Researchers), ABRA (Association of Behavioural Researchers on Asians) and cE-Bs (Centre for Environment-Behaviour Studies), Faculty of Architecture, Planning \& Surveying, Universiti Teknologi MARA, Malaysia.

DOI: https://doi.org/10.21834/ebpj.v5iSI3.2568

\subsection{Introduction}

Prolonged use of electronic devices has shown a poor effect on the ocular and extraocular muscle, known as digital eye strain (DES) or computer vision syndrome (CVS) (Parihar et al., 2016a). A significant concern has increased among optometrists worldwide regarding the comparison between digital and hard copy reading (Rosenfield, 2016). The improvements in reading technology with the use of smartphones have caused digital screen reading to be a mainstream phenomenon (Tanner, 2014). Ocularly, the eye has an ability in changing dioptre to focus at a certain distance, referred as accommodation. However, prolonged focus on an immobile object can cause the accommodation to fluctuate or not constant called micro fluctuations (Jeng et al., 2014; Monticone \& Menozzi, 2011).

There were a few factors that can affect the accommodation microfluctuation such as pupil diameter, target's distance, binocular or monocular observation of the target, astigmatism and visual fatigue (Charman \& Heron, 2015). Other factors include target form and contrast, as well as the target illuminance (Gray, Winn, \& Gilmartin, 1993). Hence, poor image quality displayed by the digital screen reading has triggered accommodation microfluctuations which caused eyes to focus harder with slower reading, less accurate and more fatigue compared to clear printed page (Dillon, Richardson, Mcknight, Grove, et. al, 1990; Mangen, Walgermo, \& Brønnick, 2013). A continuous effort by the eye muscle has created various ocular syndromes which ergonomically challenging since 1970s.

eISSN: 2398-4287C 2020. The Authors. Published for AMER ABRA cE-Bsby e-International Publishing House, Ltd., UK. This is an open access article under the CC BYNC-ND license (http://creativecommons.org/licenses/by-nc-nd/4.0/). Peer-review under responsibility of AMER (Association of Malaysian Environment-Behaviour Researchers), ABRA (Association of Behavioural Researchers on Asians) and cE-Bs (Centre for Environment-Behaviour Studies), Faculty of Architecture, Planning \& Surveying, Universiti Teknologi MARA, Malaysia.

DOI: https://doi.org/10.21834/ebpj.v5iSI3.2568 
Thus, in this research, the root mean square (RMS) of accommodation microfluctuations in digital reading via iPad with a different viewing approach has been measured before and after 5 minutes in the dark.

\subsection{Methodology}

The ethical consideration of this research had been approved by Universiti Teknologi MARA (UiTM). The study adhered to the tenet of the Helsinki Declaration. This research was a repeated cross over experimental design, which focused on the comparison of accommodation microfluctuations between two viewing conditions on near digital reading. Nineteen young adults, aged between 19 to 25 years old (mean $22.68 \pm 1.8$ years), were recruited in this study. No known ocular diseases, history of surgery or binocular vision disorder in our subjects. The refractive status was below -4.00 dioptric power $(D)$ with a mean of refractive error $-1.15 D \pm 1.5 \mathrm{D}$. All subjects achieved visual acuity of 0.00 on LogMAR with the best optical correction. The study was carried out in a well-controlled dark experimental room (room size $62.87 \mathrm{~m}^{3}$ ). Using Kyoritsu digital light meter, the room illumination was recorded approximately 5 lux throughout the study. Only light source was emitted from the iPad screen. iPad Air was used as a digital reading tool in this study. It contained special feature of application known as 'Night Shift' mode supported by recent iOS 9.3 function by fine-tuning the colour temperature of the screen display especially at night or condition with low illumination (Apple, 2018). The technology was reported to soothe the eyes of users via automatic adjustment of the display to produce warmer screen colour and reduce blue light to improve sleep quality among users of its self-luminous portable electronic devices (Nagare, Plitnick, \& Figueiro, 2018). The accommodation microfluctuations were measured by an autorefractometer with dynamic mode software (Grand Seiko WAM-5500). The high-speed mode of the autorefractometer yielded data collection at a temporal resolution of $5 \mathrm{~Hz}$ through the WCS-1 software, which connected to examiner computer via RS-232 cable (Sheppard \& Davies, 2010). The accommodation microfluctuations for both viewing conditions were quantified using Root Mean Squared (RMS) value as in Equation 1, and were compared using paired sample t-test. A lower value of RMS (near to zero) denoted lower fluctuation in accommodation response and vice versa (Charman \& Heron, 2015).

$$
R M S=\sqrt{\frac{x_{1}^{2}+x_{2}^{2}+\cdots x_{n}^{2}}{N}}
$$

Equation 1: Root Mean Square Equation

Each subject was instructed to perform digital reading using iPad Air at $40 \mathrm{~cm}$. The reading material was a Malay short stories text. The multiple texts were constructed to reduce the similarity of the target effect, and minimizing boredom. The format of the target text was Bookman Old Style font; font size, 12; the height of letter, capital letter size $2.0 \times 2.0 \mathrm{~mm}$, lowercase letter size $1.3 \times 1.5 \mathrm{~mm}$. The description of the size and the visual angle of the letter from a testing distance of $40 \mathrm{~cm}$ was calculated as shown in Figure 1 (Elliot, 1997; Grosvendor T, 2007; Wilkinson, 2006). The short stories were adapted from Berita Harian newspaper and displayed through the iPad with a screen size of $240.0 \mathrm{~mm} \times 169.5 \mathrm{~mm}$. The screen display was built with 2048-by-1536 resolution at 264 pixels per inch to produce a sharper image by a retinal display screen. The target text was under colour control and adjustment using a 'night shift' mode. The target luminance $\left(\mathrm{cd} / \mathrm{m}^{2}\right)$ for both control and night shift mode were $288.8 \mathrm{~cd} / \mathrm{m}^{2}$ and $194.4 \mathrm{~cd} / \mathrm{m}^{2}$ measured using LS100 luminance meter (Konica Minolta). The two viewing conditions included near digital reading with and without night shift mode. Subjects were dark-adapted for 10 minutes before any measurements taken to minimize any near work effect. All measurements for each subjected were completed within the same session with less than 30 minutes apart to minimize the diurnal effect. The accommodation microfluctuations were measured continuously for 60 seconds before and after 5 minutes of near digital reading in dark.

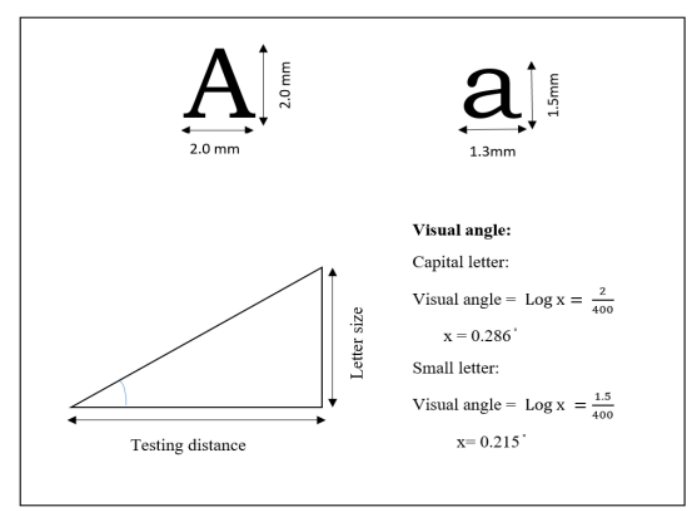

Fig. 1 : The size and the visual angle of the letter of target text used in the study (Keating, 2002). 


\subsection{Findings}

A paired-sample t-test was used to determine whether there was a statistically significant mean difference between the accommodation microfluctuations before and after 5 minutes of the iPad reading with and without night shift mode. Table 1 displayed the mean, standard deviation and statistical analysis before and after 5 minutes for both experimental conditions, which were not statistically significant $p>0.05$. There was no significant difference in accommodation microfluctuations before $(0.203 \mathrm{D} \pm 0.12 \mathrm{D})$ and $\operatorname{after}(0.201 \mathrm{D} \pm 0.13 \mathrm{D}) 5$-minute reading with night shift mode [t-value $=0.04, p>0.05$ ]. There was no significant difference in accommodation microfluctuations before $(0.26 \mathrm{D} \pm 0.28 \mathrm{D})$ and after $(0.18 \mathrm{D} \pm 0.05 \mathrm{D}) 5$-minute reading without night shift mode [tvalue $=1.165, p>0.05]$.

Table 1: Statistical comparison of the accommodation microfluctuations between digital viewing with and without night shift mode.

\begin{tabular}{|c|c|c|c|}
\hline \multicolumn{4}{|c|}{$\begin{array}{l}\text { Accommodation Microfluctuations } \\
\text { (mean and standard deviation in diopters) }\end{array}$} \\
\hline & Without night shift mode & With night shift mode & Statistics \\
\hline Before 5 mins & $0.26 \pm 0.28$ & $0.20 \pm 0.12$ & $t=1.39, p=0.18$ \\
\hline After 5 mins & $0.18 \pm 0.05$ & $0.20 \pm 0.13$ & $t=-0.61, p=0.55$ \\
\hline Statistics & $t=1.16, p=0.26$ & $t=0.04, p=0.97$ & \\
\hline
\end{tabular}

\subsection{Discussion}

Digital technology has redefined the reading and literacy in education and learning where digitization has displaced reading from its nature where the modalities and media were rooted (Mangen,2016). The written text was no longer static and linear yet has increased to a complex, multimodal, dynamic and interactive presentation such as e-book and e-learning. This has eventually led to prolonged and repeated viewing which caused discomfort by digital users known as digital eye strain (DES), or computer vision syndrome (CVS). DES may be triggered by several factors such as workstation environment, accommodation and vergence abnormalities, inadequate wetting of the corneal surface and refractive correction (Parihar et al., 2016). Moreover, extensive near digital reading in a dark condition may cause visual fatigue due to the light emitted from the screen compared the hard copy and e-ink (S. Benedetto, DraiZerbib, Pedrotti, et. al, 2013; Simone Benedetto, Carbone, Drai-Zerbib, et. al, 2014; Mangen et al., 2013). The accommodation microfluctuation value of 5-minute near digital reading with and without night shift mode in our study was found to be relatively similar. Duration of exposure might be the main factor of the insignificant comparison. However, 5 minutes of digital reading was used because most digital users tended to spend a quick digital near task before sleep in a dark condition such as checking weather and stock, updating social media and read some messages (Rosenfield, 2016). A study done in United Kingdom with 2,000 respondents has shown that user performed approximately 221 tasks per day on their smartphone, which equivalent to 4.3 minutes at one time, with the assumption of 16-hour working time per day ("Smartphone Usage Statistics 2014 - UK Survey of Smartphone Users | Tecmark," 2018). Nonetheless, this result corroborated with previous research where the ratio of a wide range of tasks with screen luminance up to 20:1 has no effect on the speed of data entry (Kokoschka \& Haubner, 1985).

Meanwhile, (Shahnavaz \& Hedman, 1984) claimed that the accommodation changes with 6 hours shifts were lower in night shift of the brighter screen compared to darker one. A recent study done by (Simmers, Gray, \& Wilkins, 2001)) has reported vice versa where the accommodation microfluctuation was reported to increase from the colored filters usage. Another possible explanation of our findings was the asymptomatic subjects used in our study. Previous research reported a difference in the mean RMS accommodation fluctuations among visual stress subjects compared to non-visual subjects in 10 second static near task focusing on different coloured lens, which mimic the night shift mode appearance (Simmers et al., 2001). Another study using Hartmann-Shack aberrometer in evaluating 10 minutes of accommodation microfluctuations via tablet and smartphone contradicted with no significant changes among their 18 healthy subjects (Moulakaki, Recchioni, Águila-Carrasco, Esteve-Taboada, \& Montés-Micó, 2017). Hence, the advantage of night shift mode for digital reading in the dark might not apparent among asymptomatic digital users.

\section{5,0 Conclusion \& Recommendations}

Our insignificant findings in the accommodation microfluctuation comparison seemed to suggest that Night Shift Mode did not display as an advantage in controlling accommodation among asymptomatic digital users. In future, a measurement of accommodation response usinglatest open field Power Refractor (Plusoptix 16) is recommended. The innovation of open field Power Refractor benefits in research of accommodation as the measurement taken is much more convenient and effective. In fact, natural reading task can be adopted by subject without the reduction of short blue wavelength will not be affected. Furthermore, the sample size of subject 
could be increased as well as the age range. Previous study had done on the refractive group but most focusing on the young adult (Moulakaki et al., 2017; Park et al., 2014). So, we suggest that the age range of children and adult to be considered in further study. The group of children and adult might give insight on further information on accommodation status in different tested condition.

\section{Acknowledgement}

This project was supported by LESTARI GRANT (Project Number: 600-IRMI/DANA KCM 5/3/LESTARI (110/2017). Grand Seiko WAM 5500 binocular auto-refractor facility was at the courtesy of Optometry and Vision Science Research Centre (iROViS).

\section{References}

Apple. (2018). Use Night Shift on your iPhone, iPad, and iPod touch. Retrieved June 29, 2018, from https://support.apple.com/en-us/ht207570 Benedetto, S., Drai-Zerbib, V., Pedrotti, M., Tissier, G., \& Baccino, T. (2013). E-readers and visual fatigue. PloS One, 8 (12)(e83676).

Benedetto, Simone, Carbone, A., Drai-Zerbib, V., Pedrotti, M., \& Baccino, T. (2014). Effects of luminance and illuminance on visual fatigue and arousal during digital reading. Computers in Human Behavior, 41(October), 112-119.

Charman, W. N., \& Heron, G. (2015). Microfluctuations in accommodation: An update on their characteristics and possible role. Ophthalmic and Physiological Optics, 35(5), 476-499.

Dillon, A., Richardson, J., Mcknight, C., Grove, E., \& Le, L. (1990). Behaviour and Information Technology, 9 (3) 215-227, 9(3), $215-227$.

Elliot, D. B. (1997). Clinical Procedure in Primary Eye Care (Second Edi). Butterworth Heinemann.

Gray, L. S., Winn, B., \& Gilmartin, B. (1993). Effect of target luminance on microfluctuations of accommodation. Ophthalmic and Physiological Optics, 13(3), $258-265$.

Grosvendor T. (2007). Primary Care Optometry. Elsevier Inc.

Jeng, W.-D., Ouyang, Y., Huang, T.-W., Duann, J.-R., Chiou, J.-C., Tang, Y.-S., \& Ou-Yang, M. (2014). Research of accommodative microfluctuations caused by visual fatigue based on liquid crystal and laser displays. Applied Optics, 53(29), H76.

Keating, M. P. (2002). Geometric, Physical, and Visual Optics (Second Edi). Butterworth-Heinemann.

Kokoschka, S., \& Haubner, P. (1985). Luminance ratio at visual display workstations and visaul performance, 17(3), 138-144.

Mangen, A., Walgermo, B. R., \& Brønnick, K. (2013). Reading linear texts on paper versus computer screen: Effects on reading comprehension. International Journal of Educational Research, 58, 61-68.

Monticone, P. P., \& Menozzi, M. (2011). A review on methods used to record and analyze microfluctuations of the accommodation in the human eye. Journal of the European Optical Society, 6(February).

Moulakaki, A. I., Recchioni, A., Águila-Carrasco, A. J. D., Esteve-Taboada, J. J., \& Montés-Micó, R. (2017). Assessing the accommodation response after near visual tasks using different handheld electronic devices. Arquivos Brasileiros de Oftalmologia, 80(1), 9-13.

Nagare, R., Plitnick, B., \& Figueiro, M. (2018). Does the iPad Night Shift mode reduce melatonin suppression? Lighting Research \& Technology, 1477153517748189.

Parihar, J. K. S., Jain, V. K., Chaturvedi, P., Kaushik, J., Jain, G., \& Parihar, A. K. S. (2016a). Computer and visual display terminals (VDT) vision syndrome (CVDTS). Medical Journal Armed Forces India, 72(3), 270-276.

Parihar, J. K. S., Jain, V. K., Chaturvedi, P., Kaushik, J., Jain, G., \& Parihar, A. K. S. (2016b). Computer and visual display terminals (VDT) vision syndrome (CVDTS). Medical Journal Armed Forces India, 72(3), 270-276.

Rosenfield, M. (2016). Computer vision syndrome (aka digital eye strain). Optometry, 17(1), 1-10.

Shahnavaz, H., \& Hedman, L. (1984). Visual accommodation changes in vdu-operators related to environmental lighting and screen quality. Ergonomics, 27(10), 10711082.

Sheppard, A. L., \& Davies, L. N. (2010). Clinical evaluation of the Grand Seiko Auto Ref/Keratometer WAM-5500. Ophthalmic and Physiological Optics, 30(2), $143-151$.

Simmers, A. J., Gray, L. S., \& Wilkins, A. J. (2001). The influence of tinted lenses upon ocular accommodation. Vision Research, 41(9), $1229-1238$.

Wilkinson, M. E. (2006). Essential Optics Review for the Boards. (A. P. Doan, Ed.). F.E.P International, Inc. 